\title{
Intensification of induction chemotherapy before consolidation chemoradiotherapy improves progression-free survival and time without treatment in patients with locally advanced pancreatic cancers
}

\author{
Nicolas Williet ${ }^{1,2}$, Thomas Di Bernardo ${ }^{1}$, Chloé Vernet ${ }^{1}$, Léa Saban Roche ${ }^{3}$, Thierry \\ Muron $^{3}$, Xavier Roblin ${ }^{1}$, Nicolas Magne ${ }^{4}$ and Jean-Marc Phelip ${ }^{1,2}$ \\ ${ }^{1}$ Hepatogastroenterology Department, University Hospital of Saint-Etienne, Saint-Etienne, France \\ ${ }^{2}$ EA 7425 HESPER, Health Services and Performance Research, Claude Bernard Lyon 1 University, Lyon, France \\ ${ }^{3}$ Medical Oncology Department, Institut Cancérologie Lucien Neuwirth, Saint-Priest-en-Jarez, France \\ ${ }^{4}$ Radiotherapy Department, Institut Cancérologie Lucien Neuwirth, Saint-Priest-en-Jarez, France \\ Correspondence to: Nicolas Williet, email: nwilliet@yahoo.fr \\ Keywords: induction chemotherapy; locally advanced; pancreatic carcinoma; radiotherapy; survival \\ Received: June 02, $2018 \quad$ Accepted: July 21, $2018 \quad$ Published: August 10, 2018 \\ Copyright: Williet et al. This is an open-access article distributed under the terms of the Creative Commons Attribution License 3.0 \\ (CC BY 3.0), which permits unrestricted use, distribution, and reproduction in any medium, provided the original author and source \\ are credited.
}

\section{ABSTRACT}

Aims: To assess the interest of induction chemotherapy (ICT) intensification before chemoradiotherapy (CRT) in patients with locally advanced pancreatic cancer.

Methods: Charts of patients treated between February 2010 and November 2016 with consolidation capecitabin based-CRT were retrospectively reviewed in this bicentric study. Patients who underwent Gemcitabine as ICT (Group G) were compared to patients treated with intensive ICT (group I). Primary objectives were progression-free survival (PFS), defined as the time from the first day of ICT to progression or last follow-up, and Time without treatment (TWT), as the time from the last day of CRT to progression.

Results: Patients' characteristics were balanced between group I (Folforinox: $n=24$; GemOx: $n=6)$ and group $G(n=16)$ including mean age (63.7 vs 68.1 years), and performance status (PS 0-1 :90\% vs 93.7\%). Median PFS (17.8 months vs 12 months; $p=0.02$ ) and TWT (7.4 months vs 2.5 months $p=0.01$ ) were statistically better in group I vs group $G$. These results remained statistically and clinically significant by comparing Folfirinox subgroup to Gemcitabine. A trend to a better median overall survival was observed in group I (20.4 months) vs group G (18.3 months; $p=0.07$ ). After adjusting for ICT duration, PS, and CA19.9 level, ICT intensification remains independently prognostic. Toxicity profile was in accordance with Literature.

Conclusion: This study shows ICT intensification before CRT is an interesting approach in patients with locally advanced pancreatic cancer. Further studies are needed to confirm these results, and to assess the specific role of CRT in this setting. 


\section{INTRODUCTION}

Pancreatic ductal adenocarcinoma (PDAC) will be the second-leading cause of cancer-related deaths in Europe and in the United-States in $2030[1,2]$. The majority are metastatic at the time of diagnosis and about $30 \%$ are locally advanced, mainly due to arterial involvement. However, this setting remains heterogenous as it regroups potentially resectable tumors and definitely unresectable tumors. These two subgroups are yet to be defined using set guidelines. The treatment's objective, however, may be different in clinical practice. In the first subgroup, 26\% of patients treated with FOLFIRINOX (leucovorin and fluorouracil plus irinotecan and oxaliplatin) experience a reduction in tumor size allowing tumor resection [3] and experience similar overall survival (OS) to those with tumor that are immediately resectable [4]. With these results in mind, tumor response rate could be the primary endpoint for these patients, and achieve up to $30 \%$ with FOLFIRINOX [3] vs $10 \%$ with Gemcitabine alone [5, 6]. In contrast, if the tumor remains unresectable after induction chemotherapy (ICT), primary objectives of the treatment should be progression-free survival (PFS) and overall survival (OS), with an acceptable toxicity profile.

Level of evidence is low regarding management of these patients. Hence, chemotherapy based Gemcitabine alone remains the standard of care for patients with locally advanced pancreatic cancer in Europe and United-states [7, 8]. After achieving disease-control with Gemcitabine based chemotherapy, capecitabinebased chemoradiotherapy (CRT) is then an acceptable therapeutic option in the goal of potentially improving the local-control rate and the time without treatment (TWT) [9], even if no benefit in terms of OS has been provided in the phase III trial LAP07 [9].

However, in the metastatic setting, two phase III randomized clinical trials showed the superiority of an intensive chemotherapy such as FOLFIRINOX or Gemcitabine + Nab-paclitaxel to Gemcitabine alone in terms of survivals and quality of life $[10,11]$. But, these results have not been evaluated yet for locally advanced PDAC. Moreover, exposing these patients, who have an 18 months median OS, to Folfirinox-related toxicity, such as distal dysesthesia or hypoesthesia, from the first day of treatment to death, may raise some questions. Hence, a growing number of prospective studies are currently carried out for assessing the benefit of chemotherapy intensification in patients with locally advanced PDAC [12-14]. In NEOPAN, a phase III study, patients are randomized between Gemcitabine vs FOLFIRINOX. Pending these results, we carried out the present study to assess retrospectively the benefit of induction chemotherapy intensification compared to Gemcitabine alone in terms of survivals and TWT, in patients with locally advanced PDAC definitively unresectable and who were fit for consolidation CRT.

\section{RESULTS}

During the period study, 144 patients with borderline or locally advanced PDAC were treated in our two centers (Flow-chart in Supplementary Figure 1): 47 with Gemcitabine alone, 56 with Folfirinox, and 17 with Gemox. Twenty-four additional patients underwent either another chemotherapy schedule or best supportive care. During the induction chemotherapy period, a total of 74 patients were excluded for disease progression $(n=53)$, secondary surgery $(n=15)$, or for PS $\geq 2(n=5)$. One death due to pulmonary embolism was observed in the Folfirinox subgroup. The 46 remaining patients were included in the population study.

\section{Characteristics of the population study at baseline}

All patients and tumor characteristics at baseline were reported in Table 1 . Of the 46 patients who were included, $16(34.8 \%)$ were treated with Gemcitabine alone and $30(65.2 \%)$ with Intensive ICT (GEMOX: $n=6$, FOLFIRINOX: $n=24)$. Patients were comparable for age (mean: 68.1 yrs \pm 8.5 and $63.7 \mathrm{yrs} \pm 6.4 ; p=$ $0.08)$, proportions of women ( $50 \%$ vs $46.7 \%$; $p=1.0$ ), cardiovascular history including ischemic myocardiopathy $(12.5 \%$ vs $3.3 \% ; p=0.53)$, performance status (PS 0: $62.5 \%$ vs $80 \% ; p=0.08)$, and blood levels of bilirubin (median: $11 \mu \mathrm{mol} / \mathrm{l}$ [7.8-18.6]), albumin (40.1g/L [37.6-43]) and CA19.9 (222.5 UI/L [45-452.8] vs 96.2UI/L [36.3-384.8]; $p=0.79)$.

Tumor was located in the head or isthmus of the pancreas in the vast majority $(84.8 \%)$. In contrast, there was a trend to less low-differenciated tumor in Group $\mathrm{G}$ $(0.0 \%)$ compared to Group I $(23.3 \% ; p=0.08)$. Similarly, median tumor size tended to be smaller in group G (30 $\mathrm{mm}$ [23-36]) vs group I (35 mm [30-42]; $p=0.08$ )

\section{Characteristics at the end of induction treatment}

Corresponding characteristics at the end of induction treatment were reported in Table 2. The following data were similar between the two groups: median ICT duration (3 months [2.7-4.5] vs 4.2 months [2.1-5.7]; $p=0.55)$, total duration of induction treatment including CRT (6.2 months [5.3-8.1] vs 6 months [5.6-8.7]; $p=0.63)$, median level of bilirubin $(6 \mu \mathrm{mol} / \mathrm{L}$ [5-9] and $6 \mu \mathrm{mol} / \mathrm{L}[4.5-8.8] ; p=0.78)$, albumin (34.5 g/L [33.1-35.8] vs $36.3 \mathrm{~g} / \mathrm{L}[33.8-40] ; p=0.67)$, CA19.9 levels (108.7UI/L [36.8-494.2] vs 57UI/L [24.1224.6]; $p=0.85)$, CA19.9 variation from baseline $(-165.5$ $[-278.8--65.9]$ vs $-3.4[-257-+20.4] ; p=0.15)$, and tumor response rate $(18.8 \%$ vs $20.0 \% ; p=1.0)$.

However, there was a trend to more PS score 0 in Group I (56.7\%) compared to the Group G (37.5\%; armitage test $p=0.08)$. In contrast, median total radiation 


\begin{tabular}{|c|c|c|c|c|}
\hline & $\begin{array}{c}\text { Total Population } \\
\quad(n=46)\end{array}$ & $\begin{array}{c}\text { Gemcitabine group } \\
(n=16)\end{array}$ & $\begin{array}{l}\text { Intensive ICT } \\
\text { group }(n=30)\end{array}$ & $P$ value \\
\hline Age, mean $( \pm$ SD) & $65.3( \pm 7.4)$ & $68.1( \pm 8.5)$ & $63.7( \pm 6.4)$ & 0.08 \\
\hline Female & $22(47.8 \%)$ & $8(50 \%)$ & $14(46.7 \%)$ & 1 \\
\hline \multicolumn{5}{|l|}{ Medical history } \\
\hline arterial hypertension & $20(43.5 \%)$ & $9(56.2 \%)$ & $11(36.7 \%)$ & 0.38 \\
\hline Diabetes mellitus & $15(32.6 \%)$ & $7(43.8 \%)$ & $8(26.7 \%)$ & 0.41 \\
\hline Ischemic myocardiopathy & $3(6.5 \%)$ & $2(12.5 \%)$ & $1(3.3 \%)$ & 0.53 \\
\hline Peripheral artery disease & $2(4.3 \%)$ & $1(6.2 \%)$ & $1(3.3 \%)$ & 1 \\
\hline Cerebrovascular accident & $2(4.3 \%)$ & $1(6.2 \%)$ & $1(3.3 \%)$ & 1 \\
\hline \multicolumn{5}{|l|}{ Performance status at baseline } \\
\hline 0 & $34(73.9 \%)$ & $10(62.5 \%)$ & $24(80 \%)$ & 0.08 \\
\hline 1 & $8(17.4 \%)$ & $5(31.2 \%)$ & $3(10 \%)$ & \\
\hline $\begin{array}{l}\text { Bilirubine at baseline, median } \\
{[\text { IQR25-75] }(\mathrm{NA}=19)}\end{array}$ & $11[7.8-18.6]$ & $11[10-32]$ & $11.8[7.3-18.3]$ & 0.68 \\
\hline $\begin{array}{l}\text { Albumine, } \\
\text { median }[\text { IQR25-75] }(\mathrm{NA}=28)\end{array}$ & $40.1[37.6-43]$ & $40.2[35.1-43]$ & $40[37.8-42.5]$ & 1 \\
\hline \multicolumn{5}{|l|}{ Tumor Localization } \\
\hline Head/isthmus/Winslow & $39(84.8 \%)$ & $15(93.8 \%)$ & $24(80 \%)$ & 0.39 \\
\hline Body/tail & $7(15.2 \%)$ & $1(6.2 \%)$ & $6(20 \%)$ & \\
\hline Tumor differenciation & & & & 0.08 \\
\hline Well to moderate & $30(65.2 \%)$ & $7(100 \%)$ & $23(76.7 \%)$ & \\
\hline Low & $7(15.2 \%)$ & $0(0 \%)$ & $7(23.3 \%)$ & \\
\hline $\begin{array}{l}\text { CA19.9 at baseline, } \\
\text { median [IQR25-75] }(\mathrm{NA}=14)\end{array}$ & $116.6[36-388.2]$ & $222.5[45-452.8]$ & $96.2[36.3-384.8]$ & 0.79 \\
\hline $\begin{array}{l}\text { CEA at baseline, } \\
\text { median [IQR25-75] }(\mathrm{NA}=22)\end{array}$ & $2.8[1.7-5]$ & $2.2[1.8-4]$ & $3.2[1.6-5.4]$ & 0.87 \\
\hline
\end{tabular}

Abbreviations: ICT: induction chemotherapy; IQR: interquartiles range; NA:Not available; SD: standard deviation

dosimetry trend to be lower in the corresponding groups (50Gy [45-50.4] vs 50.4Gy [50.4-50.4], respectively; $p=0.1)$. Median number of chemotherapy cycles was 7 cycles [6-11.7] and 4 cycles [3.5-6]), respectively.

\section{Tolerance of the treatment}

All side-effects related to ICT were reported in Figure 1. There was no grade 4 toxicity in both groups. Only Group I experienced grade 3 toxicities for diarrhea $(12.5 \%)$, alopecia $(10.0 \%)$, oxaliplatin-induced neuropathy $(8.7 \%)$, fatigue $(4.2 \%)$ and neutropenia $(4.2 \%)$. Only grade 3 for overall toxicity was significantly higher in Group I $(33.3 \%$ vs $0.0 \% ; p=0.03)$. Any grade toxicity was higher in group I vs group $\mathrm{G}$ regarding overall toxicity $(95.8 \%$ vs $68 \% ; p=0.03)$, diarrhea $(66.7 \%$ vs $8.3 \% ; p=0.001)$, and nausea/vomit ( $50 \%$ vs $8.3 \% ; p=0.03)$. In contrast, no thrombopenia was reported for group I $(0.0 \%)$ vs $25 \%$ of the patients treated with Gemcitabine $(p=0.03)$. There is no difference statistically significant between the two groups for any grade fatigue ( $66.7 \%$ vs $50 \%$ ), neutropenia $(12.5 \%$ vs $25.2 \%)$, or anemia ( $4.2 \%$ vs $8.3 \%)$.

\section{Survivals}

Thirty three progressions (Group G: 10; Group I: 23) were observed during a median 15.5 months followup. PFS (Figure 2A) was significantly superior in the Group I (median: 17.8 months; 95\% CI: 13.6-21.5) compared to Group G (12 months: $95 \%$ CI: $8.5-\mathrm{NA})$, corresponding to a reduction of the progression-risk over time by $60 \%$ ( $\mathrm{HR}=0.40 ; 95 \% \mathrm{CI}: 0.18-0.88$; $p=0.02$ ). These results remained statistically and clinically significant regarding the subgroup of patients treated with Folfirinox (17.8 months; 95\% CI: 13.6-20.7) compared to those treated with Gemcitabine alone (12.0 months; 95\% CI:8.5-NC; $p=0.037$ ) (Supplementary Figure 2A). Only ICT intensification (group G vs group I) was prognostic after univariate analyses. After adjusting on ICT duration, PS and CA19.9 level at baseline, PFS 
Table 2: Characteristics of patients at the end of induction chemotherapy

\begin{tabular}{|c|c|c|c|c|}
\hline & $\begin{array}{l}\text { Total Population } \\
\qquad(n=46)\end{array}$ & $\begin{array}{l}\text { Gemcitabine group } \\
\qquad(n=16)\end{array}$ & $\begin{array}{l}\text { Intensive ICT } \\
\text { group }(n=30)\end{array}$ & $P$ value \\
\hline $\begin{array}{l}\text { Duration of ICT, } \\
\text { months, median [IQR25-75] }\end{array}$ & $3.7[2.5-5.5]$ & $3[2.7-4.5]$ & $4.2[2.1-5.7]$ & 0.55 \\
\hline $\begin{array}{l}\text { Performance status } \\
\text { at the end of ICT }\end{array}$ & & & & 0.08 \\
\hline 0 & $23(50 \%)$ & $6(37.5 \%)$ & $17(56.7 \%)$ & \\
\hline 1 & $15(32.6 \%)$ & $7(43.8 \%)$ & $8(26.7 \%)$ & \\
\hline 2 & $1(2.2 \%)$ & $1(6.2 \%)$ & $0(0 \%)$ & \\
\hline $\begin{array}{l}\text { Bilirubin }(\mathrm{NA}=22), \\
\text { median }[\mathrm{IQR} 25-75]\end{array}$ & $6[4.8-9.2]$ & $6[5-9]$ & $6[4.5-8.8]$ & 0.78 \\
\hline $\begin{array}{l}\text { Albumin }(\mathrm{NA}=37) \\
\text { median }[\mathrm{IQR} 25-75]\end{array}$ & $36.3[33-37.7]$ & $34.5[33.1-35.8]$ & $36.3[33.8-40]$ & 0.67 \\
\hline $\begin{array}{l}\text { CA19.9 at the end of ICT } \\
(\mathrm{NA}=25), \\
\text { median [IQR25-75] }\end{array}$ & 57 [25.9-249.7] & $108.7[36.8-494.2]$ & $57[24.1-224.6]$ & 0.85 \\
\hline $\begin{array}{l}\text { Delta CA19.9 }(\mathrm{NA}=22) \text {, } \\
\text { median [IQR25-75] }\end{array}$ & $-46.9[-269.8-7.7]$ & $-165.5[-278.8--65.9]$ & $-3.4[-257-20.4]$ & 0.15 \\
\hline RECIST at the end of ICT & & & & 1 \\
\hline Progression & $3(6.5 \%)$ & $1(6.2 \%)$ & $2(6.7 \%)$ & \\
\hline Tumor response & $9(19.6 \%)$ & $3(18.8 \%)$ & $6(20 \%)$ & \\
\hline Stable & $34(73.9 \%)$ & $12(75 \%)$ & $22(73.3 \%)$ & \\
\hline $\begin{array}{l}\text { Time for ICT + CRT, } \\
\text { mean }( \pm \mathrm{SD})\end{array}$ & $7.1( \pm 2.5)$ & $6.6( \pm 1.9)$ & $7.3( \pm 2.8)$ & 0.32 \\
\hline median [IQR25-75] & $6[5.5-8.6]$ & $6.2[5.3-8.1]$ & $6[5.6-8.7]$ & 0.63 \\
\hline $\begin{array}{l}\text { Number of chemotherapy } \\
\text { Cycles, Median [IQR25-75] }\end{array}$ & - & $4[3.5-6.0]$ & $7[6-11.7]$ & - \\
\hline $\begin{array}{l}\text { Dosimetry, } \\
\text { mean }( \pm \mathrm{SD})\end{array}$ & $48.2( \pm 5.6)$ & $48.5( \pm 7.4)$ & $48.1( \pm 4.4)$ & 0.85 \\
\hline median [IQR25-75] & $50.4[45-50.4]$ & $50.4[50.4-50.4]$ & $50[45-50.4]$ & 0.1 \\
\hline
\end{tabular}

Abbreviations: CRT: chemoradiotherapy; ICT: induction chemotherapy; IQR: interquartiles range; NA:Not available; SD: standard deviation.

remains better in group I vs Group G: $\mathrm{HR}=0.12(95 \%$ CI: $0.03-0.55) ; p=0.006$.

Twenty two deaths (Group G: 7; Group I: 15) occurred during follow-up. Median OS (Figure 3) tended to be higher in the Group I (20.4 months; 95\% CI: 17.8-NA) compared to Group G (18.3 months; 95\% CI: 13.3-NA), corresponding to a reduction of deathrisk over time by $57 \%(\mathrm{HR}=0.43 ; 95 \% \mathrm{CI}: 0.17-1.09$; $p=0.08)$. This trend was not confirmed in Folfirinox subgroup (median OS: 19.0 months; 95\% CI: 16.9-NC; $p$ $=0.21$ (Supplementary Figure 3 ). There is no other factor impacting on OS.

\section{Time without treatment (Figure 2B)}

From the last day of CRT, median TWT was higher in Group I (7.4 months; 95\% CI: 5.8-17.3) compared to Group G (2.5 months; 95\% CI: $2.5-\mathrm{NA} ; p=0.01)$, corresponding to a reduction over time by $64 \%(\mathrm{HR}=0.36$; 95\% CI: 0.16-0.80). These results remained statistically and clinically significant by comparing subgroup of patients treated with Folfirinox to those with Gemcitabine alone (median TWT): 6.4 months (5.8-15.3) vs 2.7 months $(2.5-\mathrm{NC}) ; p=0.028$ (Supplementary Figure $2 \mathrm{~B})$. Univariate analyses showed ICT intensification $(p=0.01)$, bilirubin level at the end of CRT ( $p=0.004)$, total dosimetry $(p=0.1)$ and number of fractions $(p=0.13)$ were prognostic for the TWT. These variables, adjusted on duration of induction period and PS at the last day of ICT, remain statistically prognostic (Table 3 ), with a negative impact on the TWT by cumulated radiation dose $(\mathrm{HR}=1.73 ; 95 \% \mathrm{CI}: 1.03-2.9 ; p=0.04)$, and bilirubin level $(\mathrm{HR}=1.23 ; 95 \% \mathrm{CI}: 1.09-1.41 ; p=0.001)$. In contrast, 
intensive ICT $(\mathrm{HR}=0.05 ; 95 \% \mathrm{CI}: 0.01-0.34 ; p=0.003)$, and number of fractions $(\mathrm{HR}=0.37 ; 95 \% \mathrm{CI}$ : $0.15-0.95$; $p=0.04)$ were positive prognostic factors. Of the 33 disease-progressions observed within follow-up, 21 involved at least the primitive tumor (63.6\%). Local progression rates tended to be higher in the Group $\mathrm{G}$ $(90.0 \%)$ vs Group I $(59.1 \% ; p=0.11)$.

\section{Treatment at progression}

Regarding treatment at progression, data missed for 6 patients in both groups. In group G, 3 patients could be treated with a second line therapy such as FOLFIRI $(n=1)$ or FOLFOX $(n=2)$. In group I, 6 patients resumed a lighter front line regimen (subgroup FOLFIRINOX: $n=3$ FOLFOX; $n=2$ FOLFIRI) (subgroup GEMOX: $n=1$ Gemcitabine alone). Twelve other patients underwent a second-line therapy (subgroup FOLFIRINOX: $n=6$ Gemcitabine alone; $n=3$ Gemcitabine + Nab-paclitaxel) (Subgroup GEMOX: $n=2$ Folfirinox, $n=1$ Folfiri).
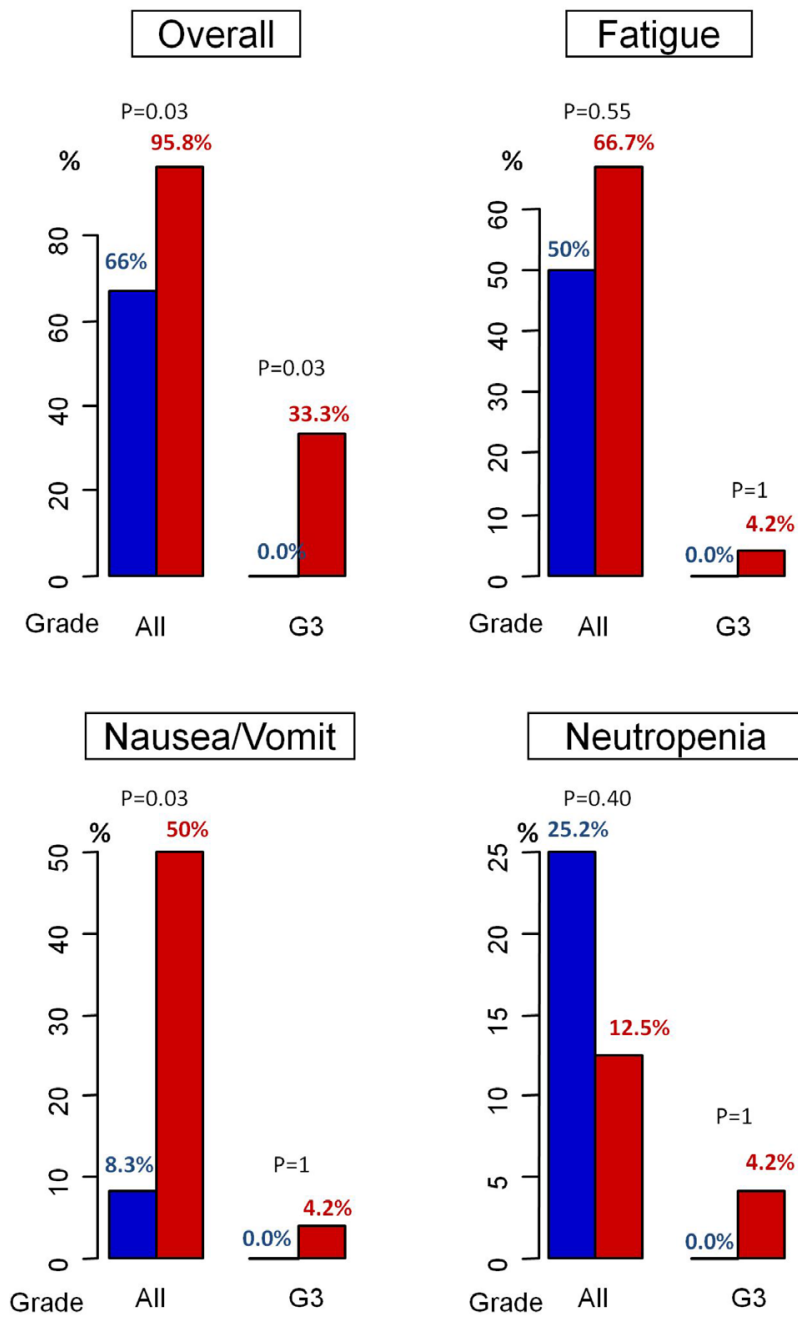

Overall, patients could be treated with chemotherapy at progression in a statistically higher proportion in the Group I $(60.0 \%)$ compared to the Group G $(16.6 \% ; p=0.02)$.

\section{DISCUSSION}

Management of patients with locally advanced PDAC remains debatted. Indeed, the level of evidence remains low in this setting. Induction chemotherapy by Gemcitabine is currently the standard of care. However, intensive chemotherapy schedules (FOLFIRINOX or Gemcitabine + Nab-Paclitaxel) are frequently used in clinical practice, because their superiority to Gemcitabine alone was well demonstrated in two phase III trials either in terms of PFS or OS $[10,15]$. The second reason of intensification ICT in clinical practice is probably the secondary resection rates that achieve up to $26 \%$ with FOLFIRINOX [3] or $15 \%$ to $28.6 \%$ with the combination Gemcitabine + Nab-Paclitaxel [13, 14]. Hence, a
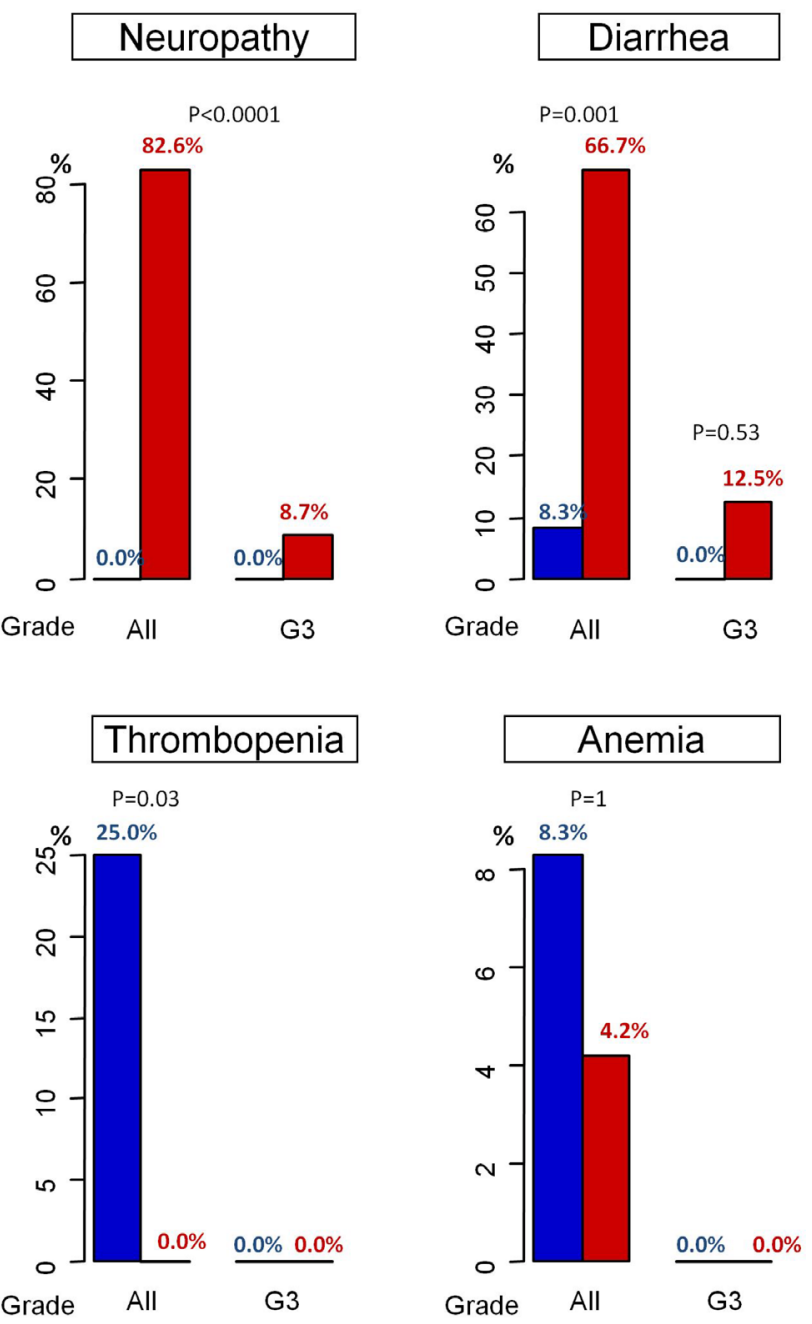

Intensive ICT

Figure 1: Chemotherapy-related toxicities. 
growing number of prospective studies are evaluating these schedules in this setting. To date, the two largest prospective studies evaluating FOLFIRINOX in patients with locally advanced PDAC showed a median overall PFS ranging from 13 to 16 months and a median OS from 22 to 25 months $[16,17]$. About $2 / 3$ of these patients underwent consolidation CRT. Hence, results of our study is in accordance with literature. However, our population was more selected because we excluded all patients who underwent secondary surgery after tumor shrinkage with ICT, those who were not fit for consolidation CRT at the end of the induction period and all patients who experienced disease-progression within induction period. This method of selection allowed to make well-

A Progression-free survival
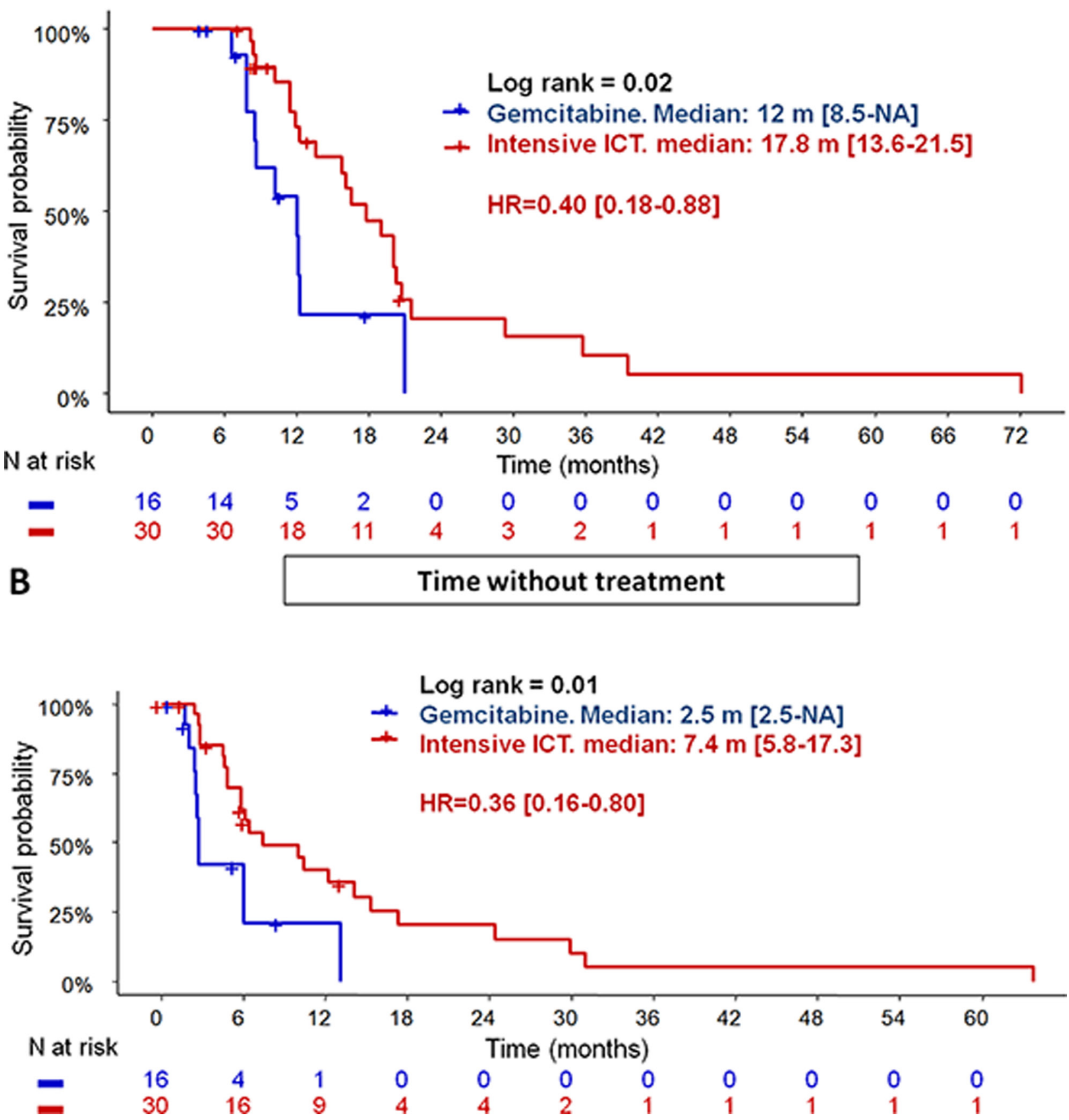

Figure 2: Progression-free survival (A) and time without treatment (B) in patients treated with intensive chemotherapy induction (Gemox or Folfirinox) vs Gemcitabine. 
balanced the two groups regarding tumor characteristics, its potential evolution during the induction period and patients' characteristics. Indeed, all patients who are fit for GEMCITABINE alone are not necessarily fit for FOLFIRINOX, nor for GEMOX. Due to the retrospective nature of the present study, non-intent-totreat analysis was conducted to make the two groups as similar as possible. However, despite the non statistical significance, absolute values of PS-0 (62.5\% in the group $\mathrm{G}$ vs $80 \%$ in group I) and CA 19-9 (median: 222.5 vs 96.2UI/L) remain important and are very powerfull negative prognostic factors for survival. But, there is a relevant number of missed-data regarding CA19.9 value. Moreover, ICT intensification remains independently prognostic after adjusting for ICT duration, PS, CA19.9 value at the end of ICT.

Hence, we showed for the first time the yield of ICT intensification to Gemcitabine alone in terms of PFS and more interestingly regarding TWT. Indeed, TWT (or time to progression from the end of CRT) appears to us a more relevant objective for these patients to improve their quality of life. Moreover, chemotherapy-related toxicities were manageable, including rare grade 3 oxaliplatininduced neuropathy (8.7\%), and more fatigue in Group I compared to Group $\mathrm{G}$ without reaching the statistical significance. Interestingly, these related-chemotherapy toxicities did not reduce the possibility of treatment resumption, and OS tended to be higher in Group I although there were more low-differentiated tumor in this group.
The main limit of our study is its small size, thereby reducing the statistical power to demonstrate that Intensive ICT induced more any grade fatigue and grade 3 diarrhea. In contrast, despite this limit, survival results of the present study are clinically and statistically in favor of ICT intensification which support current clinical practice. Due to this limit we also failed to demonstrate the improvement of local-progression rates observed in favor of the ICT intensification $(59.1 \%$ vs $90.0 \%$; $p=0.11)$. However, this point is crucial as we know how such local-progression can limit or delay treatment resumption in clinical practice. Then, this difference in terms of local-progression rates may also explained the statistically lower rate of treatment resumption observed in Group G vs group I ( $16.6 \%$ vs $60.0 \%$; $p=0.02)$.

Another limit of the present study is its retrospective nature and the selection method that is not in intent-totreat. Hence, exclusion of patients presenting a tumor shrinkage allowing surgery as well as patients with tumor progression during the induction period represent a major bias. Moreover, the period of inclusion is long and is overlapping with a strong change of clinical practice, as Folfirinox was validated in 2011. Some of patients $(n=6)$ from the group I were treated by GEMOX, basing on results from previous phase III randomized clinical trials that showed improvement of overall response rate (27-31\%) with GEMOX vs Gemcitabine alone (4-15\%). In our study, half of these patients were treated in 2011 that is before PRODIGE4/ACCORD11 publication [10]. The 3 remaining patients who were treated after 2011 were

\section{Overall survival}

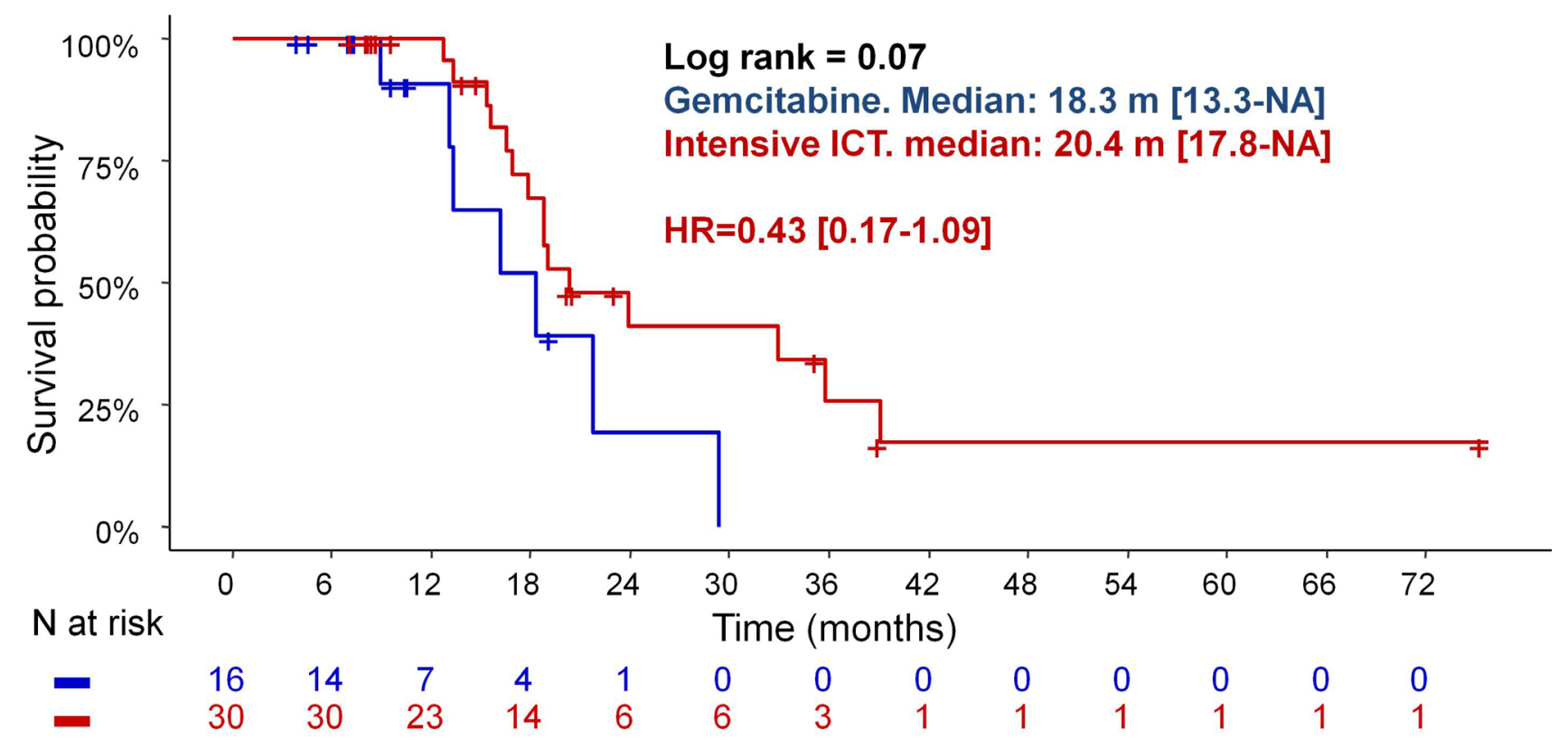

Figure 3: Overall survival in patients treated with intensive chemotherapy induction (Gemox or Folfirinox) vs Gemcitabine. 
Table 3: Uni- and multivariate analyses by cox regression for time without treatment

\begin{tabular}{|c|c|c|c|c|}
\hline \multirow{2}{*}{$\begin{array}{l}\text { Univariate analyses } \\
\text { Variables }\end{array}$} & \multirow[b]{2}{*}{$P$ value } & \multirow[b]{2}{*}{ HR $[95 \%$ CI] } & \multicolumn{2}{|c|}{ Multivariate analyses } \\
\hline & & & $P$ value & HR $(95 \%$ CI) \\
\hline \multicolumn{5}{|l|}{ Clinic parameters at baseline } \\
\hline Age & 0.48 & $1.02[0.97-1.07]$ & & \\
\hline Sex & 0.97 & $0.98[0.47-2.06]$ & & \\
\hline arterial hypertension & 0.44 & $1.32[0.65-2.69]$ & & \\
\hline Diabetes mellitus & 0.97 & $1.01[0.48-2.16]$ & & \\
\hline Ischemic myocardiopathy & 0.56 & $1.54[0.36-6.59]$ & & \\
\hline Peripheral artery disease & 0.95 & $1.07[0.14-8.03]$ & & \\
\hline Cerebrovascular accident & 0.99 & $0[0-$ Inf $]$ & & \\
\hline Performance status & 0.7 & $0.78[0.23-2.7]$ & & \\
\hline \multicolumn{5}{|c|}{ Biologic parameters at baseline } \\
\hline Bilirubin level & 0.60 & $1[0.98-1.01]$ & & \\
\hline Albumine level & 0.27 & $1.06[0.96-1.18]$ & & \\
\hline CA19.9 & 0.34 & $1[1-1]$ & & \\
\hline CEA & 0.56 & $0.97[0.87-1.08]$ & & \\
\hline \multicolumn{5}{|l|}{ Tumor characteristics } \\
\hline Tumor differenciation & 0.36 & $0.59[0.19-1.83]$ & & \\
\hline Tumor localization & 0.32 & $1.63[0.62-4.29]$ & & \\
\hline \multicolumn{5}{|l|}{ Induction therapy schedule } \\
\hline Intensive ICT & 0.01 & $0.36[0.16-0.8]$ & 0.003 & $0.05[0.01-0.34]$ \\
\hline Time for ICT & 0.99 & $1[0.82-1.22]$ & 0.68 & $1.07[0.77-1.51]$ \\
\hline Dosimetry & 0.1 & 1.08 [0.99-1.17] & 0.04 & $1.73[1.03-2.9]$ \\
\hline Number of fraction & 0.13 & $1.13[0.96-1.32]$ & 0.04 & $0.37[0.15-0.95]$ \\
\hline Time for CRT & 0.64 & $1.04[0.89-1.21]$ & & \\
\hline Center & 0.94 & $0.97[0.48-1.98]$ & & \\
\hline \multicolumn{5}{|c|}{ Induction therapy tolerance to the end of ICT period } \\
\hline Performance status & 0.92 & $1.04[0.49-2.2]$ & 0.052 & $0.19[0.04-1.01]$ \\
\hline Grade 3-4 Overall toxicity & 0.32 & $0.83[0.58-1.19]$ & & \\
\hline Bilirubin level & 0.004 & 1.11 [1.03-1.19] & 0.001 & $1.23[1.09-1.41$ \\
\hline Albumine level & 0.66 & $0.97[0.82-1.13]$ & & \\
\hline \multicolumn{5}{|c|}{ Tumor response at the end of ICT period } \\
\hline CA19.9 & 0.51 & $1[1-1]$ & & \\
\hline Delta CA19.9 from baseline & 0.34 & $1[1-1]$ & & \\
\hline Tumor response (RECIST) & 0.96 & $1.03[0.27-3.91]$ & & \\
\hline Stability disease (RECIST) & 0.18 & $0.43[0.12-1.49]$ & & \\
\hline
\end{tabular}

probably not fit for FOLFIRINOX. However, although GEMOX remains a therapeutic option according to the National Comprehensive Cancer Network ${ }^{\circledR}\left(\mathrm{NCCN}^{\circledR}\right)$ guidelines [7], its use has become rare in this setting in clinical practice because no benefit was demonstrated in metastatic setting regarding overall survival $[6,18]$.

In our study, no patient was treated with the Nabpaclitaxel + Gemcitabine combination. In France, Nab-Paclitaxel is not refunded. Only a few number of centers such ours can funding this nano-drug but only for the treatment of patients with PDAC in metastatic setting. Recent prospective studies, such as LAPACT [14], have provided promising survival results with this combination therapy in locally advanced PDAC: about 8 months for the median time to treatment failure. Some of these patients underwent CRT. The remaining patients continued the combination until progression or underwent laparotomy to assess whether surgical resection of the 
tumor was feasible (15\%). Another phase II prospective study, NEOLAP, randomized patients to Gemcitabine + Nab-Paclitaxel or FOLFIRINOX in this setting: interim results were recently reported and secondary resectability in locally advanced PDAC appeared similar between the two groups [13]. Finally, only results from the phase III study NEOPAN [12] will provide robust data pros or cons the intensification of ICT in patients with locally advanced PDAC. Pending, our study provides encouraging results supporting this approach.

\section{MATERIALS AND METHODS}

\section{Population study}

All patients with locally advanced PDAC, treated consecutively between February 2010 and November 2016 in the University hospital of Saint-Etienne or in the Institut Cancérologie Lucien Neuwirth were retrospectively reviewed. Only patients who underwent induction chemotherapy for 2 to 6 months followed by Capecitabine-based chemoradiotherapy $(830 \mathrm{mg} / \mathrm{m} 2$ orally, twice daily on days 1-21 of a 28 day cycle) were included. CRT was proposed only if disease-control was achieved and if patient's PS ranged from 0 to 1 . Hence, all patients who experienced tumor progression within the induction period were excluded as well as those who achieved tumor shrinkage allowing secondary resection.

Two groups of patients were compared, according to the intensity level of ICT: the first one (Group G) involved patients who were treated with Gemcitabine alone (1000 mg/m² weekly, 3 consecutive weeks on 4$)$; the second one (Group I) involved patients who were treated with combination chemotherapy such as: Gemcitabine $\left(1000 \mathrm{mg} / \mathrm{m}^{2}\right)+$ oxaliplatin $\left(100 \mathrm{mg} / \mathrm{m}^{2}\right)$ [GEMOX] or 5 Fluorouracil (Bolus: $400 \mathrm{mg} / \mathrm{m}^{2}$; IV infusion: $2400 \mathrm{mg} / \mathrm{m}^{2}$ for $\left.46-48 \mathrm{H}\right)+$ Leucovorin $\left(400 \mathrm{mg} / \mathrm{m}^{2}\right)+$ Oxaliplatin $(85 \mathrm{mg} / \mathrm{m} 2)+$ irinotecan $\left(150-180 \mathrm{mg} / \mathrm{m}^{2}\right)$ [FOLFIRINOX]. To make these groups as similar as possible, we also excluded patients who were not fit for consolidation CRT.

\section{Data collection}

All clinical, biological, pathologic and radiological data were retrospectively collected from electronic patient's chart. Some informations, such events or some biological data before 2011, were extracted from paper charts. This study was approved by local ethical committee (IRBN632017/CHUSTE) and conducted in agreement with the «Loi informatique et libertés» (January 6, 1978, modified by the July 1, 1994 law and finalized by the August 6, 2004 law).

PFS was defined as the time from the first day of ICT to the time of disease-progression or last follow-up. Similarly, OS was defined as the time from the first day of
ICT to death or last follow-up, and TWT as the time from the last day of CRT to the time of disease-progression or last follow-up.

\section{Statistical analyses}

The primary objective of the present study was PFS and TWT. Secondary objectives were OS, chemotherapyrelated toxicities, local-progression rates, and treatments at progression. Survivals were estimated using the Kaplan-Meier method and compared with Log-Rank tests. Prognostic factors were identified using Cox proportional hazards regression by adjusting on ICT duration, PS and CA19.9 level at the last day of CRT for TWT and on corresponding data at baseline for survivals.

Qualitative variables were reported as numbers and percentages, and compared by using chisq or fisher exact test as appropriate. Percentages of ordinal variables were compared using Cochrane-Armitatge test. Quantitative variables were reported as median value with their interquartile ranges from $25 \%$ to $75 \%$, and compared by using Mann-Whitney wilcoxon test. Some of them were additionnaly reported as mean value with standard deviation (SD). All statistical analyses were performed using $\mathrm{R}$, version 3.2.2 (R project, Auckland, New Zealand).

\section{CONCLUSIONS}

The present study supports the benefit of ICT intensification in patients with locally advanced PDAC, both in terms of PFS and, more interestingly, for time without treatment. Chemotherapy-related toxicities were acceptable and in accordance with literature. Further studies are needed to confirm these results, and to assess the specific role of CRT in this setting.

\section{Abbreviations}

ICT: induction chemotherapy; CI: Confidence interval; CRT: Chemoradiotherapy; HR: Hazard ratio; IQR: Interquartile range; NA: Not available; OS: Overall survival; PDAC: Pancreatic duct adenocarcinoma; PFS: Progression-free survival; PS: Performance status; SD: Standard deviation.

\section{Author contributions}

NW: conception of the study, study supervision, data collection, statistical analyses and drafting the manuscript; TDB: data collection and drafting the manuscript. CV, NB, LSR, TM: data collection; XR, NM, JMP: interpretation of data and critical review of the manuscript, All of the authors approved the final version of the manuscript. 


\section{ACKNOWLEDGMENTS}

None.

\section{CONFLICTS OF INTEREST}

None.

\section{FUNDING}

None.

\section{REFERENCES}

1. Rahib L, Smith BD, Aizenberg R, Rosenzweig AB, Fleshman JM, Matrisian LM. Projecting cancer incidence and deaths to 2030: the unexpected burden of thyroid, liver, and pancreas cancers in the United States. Cancer Res. 2014; 74:2913-21. https://doi.org/10.1158/0008-5472. CAN-14-0155.

2. Malvezzi M, Carioli G, Bertuccio P, Rosso T, Boffetta P, Levi F, La Vecchia C, Negri E. European cancer mortality predictions for the year 2016 with focus on leukaemias. Ann Oncol. 2016; 27:725-31. https://doi.org/10.1093/annonc/ mdw022.

3. Suker M, Beumer BR, Sadot E, Marthey L, Faris JE, Mellon EA, El-Rayes BF, Wang-Gillam A, Lacy J, Hosein PJ, Moorcraft SY, Conroy T, Hohla F, et al. FOLFIRINOX for locally advanced pancreatic cancer: a systematic review and patient-level meta-analysis. Lancet Oncol. 2016; 17:80110. https://doi.org/10.1016/S1470-2045(16)00172-8.

4. Gillen S, Schuster T, Meyer Zum Büschenfelde C, Friess $\mathrm{H}$, Kleeff J. Preoperative/neoadjuvant therapy in pancreatic cancer: a systematic review and meta-analysis of response and resection percentages. PLoS Med. 2010; 7:e1000267. https://doi.org/10.1371/journal.pmed.1000267.

5. Rocha Lima CM, Green MR, Rotche R, Miller WH, Jeffrey GM, Cisar LA, Morganti A, Orlando N, Gruia G, Miller LL. Irinotecan plus gemcitabine results in no survival advantage compared with gemcitabine monotherapy in patients with locally advanced or metastatic pancreatic cancer despite increased tumor response rate. J Clin Oncol. 2004; 22:3776-83. https://doi.org/10.1200/JCO.2004.12.082.

6. Louvet C, Labianca R, Hammel P, Lledo G, Zampino MG, André T, Zaniboni A, Ducreux M, Aitini E, Taïeb J, Faroux R, Lepere C, de Gramont A; GERCOR; GISCAD. Gemcitabine in combination with oxaliplatin compared with gemcitabine alone in locally advanced or metastatic pancreatic cancer: results of a GERCOR and GISCAD phase III trial. J Clin Oncol. 2005; 23:3509-16. https://doi. org/10.1200/JCO.2005.06.023.

7. Tempero MA, Malafa MP, Al-Hawary M, Asbun H, Bain A, Behrman SW, Benson AB 3rd, Binder E, Cardin DB, Cha C, Chiorean EG, Chung V, Czito B, et al. Pancreatic Adenocarcinoma, Version 2.2017, NCCN Clinical Practice
Guidelines in Oncology. J Natl Compr Canc Netw. 2017; 15:1028-1061. https://doi.org/10.6004/jncen.2017.0131.

8. Ducreux M, Cuhna AS, Caramella C, Hollebecque A, Burtin P, Goéré D, Seufferlein T, Haustermans K, Van Laethem JL, Conroy T, Arnold D; ESMO Guidelines Committee. Cancer of the pancreas: ESMO Clinical Practice Guidelines for diagnosis, treatment and follow-up. Ann Oncol. 2015; 26:v56-68. https://doi.org/10.1093/annonc/mdv295.

9. Hammel P, Huguet F, van Laethem JL, Goldstein D, Glimelius B, Artru P, Borbath I, Bouché O, Shannon J, André T, Mineur L, Chibaudel B, Bonnetain F, et al; LAP07 Trial Group. Effect of Chemoradiotherapy vs Chemotherapy on Survival in Patients With Locally Advanced Pancreatic Cancer Controlled After 4 Months of Gemcitabine With or Without Erlotinib: The LAP07 Randomized Clinical Trial. JAMA. 2016; 315:1844-53. https://doi.org/10.1001/ jama.2016.4324.

10. Conroy T, Desseigne F, Ychou M, Bouché O, Guimbaud R, Bécouarn Y, Adenis A, Raoul JL, Gourgou-Bourgade S, de la Fouchardière C, Bennouna J, Bachet JB, KhemissaAkouz F, et al; Groupe Tumeurs Digestives of Unicancer; PRODIGE Intergroup. FOLFIRINOX versus gemcitabine for metastatic pancreatic cancer. N Engl J Med. 2011; 364:1817-25. https://doi.org/10.1056/NEJMoa1011923.

11. Von Hoff DD, Ramanathan RK, Borad MJ, Laheru DA, Smith LS, Wood TE, Korn RL, Desai N, Trieu V, Iglesias JL, Zhang H, Soon-Shiong P, Shi T, et al. Gemcitabine plus nab-paclitaxel is an active regimen in patients with advanced pancreatic cancer: a phase I/II trial. J Clin Oncol. 2011; 29:4548-54. https://doi.org/10.1200/ JCO.2011.36.5742.

12. A Randomized Phase III Trial Comparing Folfirinox to Gemcitabine in Locally Advanced Pancreatic Carcinoma (NEOPAN). ClinicalTrials.gov identifier (NCT number): NCT02539537. Available from: https:/clinicaltrials.gov/ ct2/show/NCT02539537.

13. Kunzmann V, Martens UM, Alguel H, Siveke JT, Goekkurt E, Pelzer U, Siegler GM, Hennes E, Waldschmidt D, Jakobs R, Ferenczy P, Keller R, Boeck SH, et al. Secondary resectability in locally advanced pancreatic cancer (LAPC) after nab-paclitaxel/gemcitabine- versus FOLFIRINOXbased induction chemotherapy: Interim results of a randomized phase II AIO trial (NEOLAP). J Clin Oncol. 2018; 36:348-348.

14. Pascal H, Jill L, Fabienne P, Alberto S, Beatriz GP, Edward K, Fernando R, Luis MJ, Eric T, Venu B, Scot D, Jamil A, Jack SL, et al. P-272: The international, open-label, multicenter phase 2 LAPACT trial of nab-paclitaxel (nab-P) plus gemcitabine (Gem) for patients with locally advanced pancreatic cancer (LAPC). Ann Oncol. 2016; 27:ii78-ii79.

15. Von Hoff DD, Ervin T, Arena FP, Chiorean EG, Infante J, Moore M, Seay T, Tjulandin SA, Ma WW, Saleh MN, Harris M, Reni M, Dowden S, et al. Increased survival in pancreatic cancer with nab-paclitaxel plus gemcitabine. N 
Engl J Med. 2013; 369:1691-703. https://doi.org/10.1056/ NEJMoa1304369.

16. Marthey L, Sa-Cunha A, Blanc JF, Gauthier M, Cueff A, Francois E, Trouilloud I, Malka D, Bachet JB, Coriat R, Terrebonne E, De La Fouchardière C, Manfredi S, et al. FOLFIRINOX for locally advanced pancreatic adenocarcinoma: results of an AGEO multicenter prospective observational cohort. Ann Surg Oncol. 2015; 22:295-301. https://doi.org/10.1245/s10434-014-3898-9.

17. Sadot E, Doussot A, O'Reilly EM, Lowery MA, Goodman KA, Do RK, Tang LH, Gönen M, D’Angelica MI, DeMatteo RP, Kingham TP, Jarnagin WR, Allen PJ. FOLFIRINOX Induction Therapy for Stage 3 Pancreatic
Adenocarcinoma. Ann Surg Oncol. 2015; 22:3512-21. https://doi.org/10.1245/s10434-015-4647-4.

18. Poplin E, Feng Y, Berlin J, Rothenberg ML, Hochster H, Mitchell E, Alberts S, O’Dwyer P, Haller D, Catalano P, Cella D, Benson AB 3rd. Phase III, randomized study of gemcitabine and oxaliplatin versus gemcitabine (fixeddose rate infusion) compared with gemcitabine (30-minute infusion) in patients with pancreatic carcinoma E6201: a trial of the Eastern Cooperative Oncology Group. J Clin Oncol. 2009; 27:3778-85. https://doi.org/10.1200/ JCO.2008.20.9007. 